\title{
Memory accessibility shapes explanation: Testing key claims of the inherence heuristic account
}

\author{
Larisa J. Hussak ${ }^{1}$. Andrei Cimpian ${ }^{2}$
}

Published online: 23 August 2017

(C) Psychonomic Society, Inc. 2017

\begin{abstract}
People understand the world by constructing explanations for what they observe. It is thus important to identify the cognitive processes underlying these judgments. According to a recent proposal, everyday explanations are often constructed heuristically: Because people need to generate explanations on a moment-by-moment basis, they cannot perform an exhaustive search through the space of possible reasons, but may instead use the information that is most easily accessible in memory (Cimpian \& Salomon 2014a, b). In the present research, we tested two key claims of this proposal that have so far not been investigated. First, we tested whether - as previously hypothesized - the information about an entity that is most accessible in memory tends to consist of inherent or intrinsic facts about that entity, rather than extrinsic (contextual, historical, etc.) facts about it (Studies 1 and 2). Second, we tested the implications of this difference in the memory accessibility of inherent versus extrinsic facts for the process of generating explanations: Does the fact that inherent facts are more accessible than relevant extrinsic facts give rise to an inherence bias in the content of the explanations generated (Studies 3 and 4)? The findings supported the proposal that everyday explanations are generated in part via a heuristic process that relies on easily accessible - and often inherent-information from memory.
\end{abstract}

Keywords Explanation $\cdot$ Heuristics $\cdot$ Inherence heuristic · Memory $\cdot$ Accessibility

Andrei Cimpian

andrei.cimpian@nyu.edu

University of Illinois, Urbana, IL, USA

2 New York University, New York, NY, USA
The ability to generate explanations allows people to abstract meaning from everyday experiences. From a young age, we make sense of the world by seeking to explain what we observe and what we hear from others (e.g., Carey, 1985; Gelman, 2003; Gopnik, 1998; Keil, 2006; Lombrozo, 2012; Wellman, 2011). What underlies the ability to explain? The literature on this topic has provided many insights into the workings of everyday explanations, including their typical structure (i.e., the "ingredients" that go into a satisfying explanation; e.g., Lombrozo, 2007; Lombrozo \& Carey, 2006; Sloman, 2005) and their influence on learning (e.g., Chi, Bassok, Lewis, Reimann, \& Glaser, 1989; Legare \& Lombrozo, 2014; Lombrozo \& Gwynne, 2014; Murphy \& Allopenna, 1994).

Comparatively speaking, however, research on the processes by which people generate explanations is relatively scarce (but see the literature on the related problem of generating causal hypotheses; e.g., Ahn, Kalish, Medin, \& Gelman, 1995; Johnson \& Keil, 2014; Lagnado \& Sloman, 2006). Perhaps one of the most significant omissions in the recent work on explanation has concerned the ways in which the dynamics of memory retrieval shape the search for explanations. Even though making sense of most observations requires that reasoners access the knowledge stored in longterm memory (e.g., Lombrozo, 2006, 2012), the research on explanations has seldom explored systematically the influence of retrieval processes on these judgments. Motivated in part by this gap, a recent proposal has highlighted one crucial aspect of the link between memory and explanation by positing that explanations are often generated by relying primarily on the information that is easily accessible in memory - the hallmark of a heuristic process (Cimpian, 2015; Cimpian \& Salomon, 2014a, b; see also Evans, 2006; Kahneman, 2011). Importantly, this easily accessible information is further hypothesized to be biased toward inherent or intrinsic facts about 
the entities in the observation being explained, which in turn biases the content of the explanations generated toward such inherent facts.

A few predictions of this inherence heuristic proposal have already found support. For example, as with many heuristic processes, reliance on this explanatory shortcut is stronger in participants with lower cognitive resources or lower motivation for effortful thought (e.g., Hussak \& Cimpian, 2015; Salomon \& Cimpian, 2014; Sutherland \& Cimpian, 2015). However, the research to date has provided no direct test of the key claims that (1) inherent information is highly accessible in memory and (2) due to this accessibility advantage, inherent information is overused when constructing explanations. The present studies tested these claims. Before detailing these studies, we briefly review the inherence heuristic proposal, which we then situate in the context of relevant prior research.

\section{The inherence heuristic}

What are heuristics? Heuristic reasoning is characterized by a reliance on information that comes to mind readily, even on occasions when this information is not appropriate —or at least not sufficient - for generating a correct judgment (e.g., Evans, 2006, 2008; Evans \& Stanovich, 2013; Kahneman, 2011; Kahneman \& Frederick, 2002; Shah \& Oppenheimer, 2008; Stanovich \& West, 2000). People tend to use such heuristic reasoning as a means of generating quick, approximate solutions to a wide range of complex problems that arise in daily life (for reviews, see Gilovich, Griffin, \& Kahneman, 2002; Kahneman, 2011; Stanovich \& West, 2000).

To be more precise, the distinguishing feature of heuristic reasoning is its reliance on effort-reducing steps such as substituting a simpler, easier-to-access attribute (e.g., present mood) for a more complex one (e.g., general life satisfaction) or considering only the subset of attributes that immediately come to mind to form a judgment that would otherwise require integrating more information (e.g., Kahneman \& Frederick, 2002; Schwarz \& Clore, 1983; Shah \& Oppenheimer, 2008). Most of the "classic" heuristics described in the judgment and decision making literature, such as availability (A. Tversky \& Kahneman, 1973, 1974), representativeness (Kahneman \& Tversky, 1973; A. Tversky \& Kahneman, 1974), and anchoring and adjustment (A. Tversky \& Kahneman, 1974), are nowadays understood as particular instantiations of such effort-reducing processes (Kahneman, 2011). For example, when people erroneously judge the probability that Linda is a feminist bank teller to be higher than the probability she is a bank teller (the representativeness heuristic; Tversky \& Kahneman, 1983), they are-without realizing it-substituting a simple judgment (Linda's similarity to the stereotypical feminist) for a more complicated one concerning probabilities. This spontaneous tendency to fall back on simple, easy-toaccess information is a basic feature of human reasoning.

Explanation as a heuristic process Here, we propose that heuristic effort-reduction processes also underlie how many everyday explanations are generated (Cimpian, 2015; Cimpian \& Salomon, 2014a, b). Questions about why things around us are a certain way (e.g., why have more men than women been recognized as geniuses?) are complex. Complete answers to many such questions are difficult, if not impossible, to construct on the spot. It is likely, then, that explanations generated in everyday life often rely on some effort-reducing shortcuts. In particular, people may use only a small subset of the information that is in principle relevant to an explanation - that is, they might use only whatever information happens to be easily accessible in memory when a "why?" question is being considered (e.g., geniuses have exceptional intellectual abilities - perhaps there are gender differences in these abilities). Even though heuristic explanations of this sort frequently fail to take into account relevant but harder-to-access information (e.g., historical constraints on women's ability to cultivate and express their intellects, or societal stereotypes against women's intellectual abilities; e.g., Bian, Leslie, \& Cimpian, 2017), they nevertheless tend to be perceived as satisfactory, because evaluation of the outputs of heuristic (or Type 1) processes by higher-level, analytic processes is often perfunctory (e.g., Evans, 2006; Evans \& Stanovich, 2013; Kahneman, 2011; see also Rozenblit \& Keil, 2002). ${ }^{1}$

Building on this dual-process (heuristic vs. analytic) framework, the inherence heuristic account (Cimpian \& Salomon, 2014a, b) makes a further claim about the constraints imposed by memory retrieval on the process of generating explanations. The claim is that the most accessible facts - those that are likely to be called up from memory most often and most quickly when constructing explanations - are inherent or intrinsic facts about the entities in the explanandum (e.g., men's and women's presumed cognitive abilities).

Defining inherence Simply put, inherent or intrinsic facts about a thing are facts that a reasoner represents as being "entirely about that thing," whereas extrinsic facts involve other entities in some way (e.g., Lewis, 1983, p. 197; see also Barr \& Caplan, 1987; Caplan \& Barr, 1991; Weatherson \& Marshall, 2014). For example, the claim that women generally lack

\footnotetext{
${ }^{1}$ To be clear, we do not claim that all explanations involve effort-saving shortcuts. The answers to some "why?" questions will undoubtedly be generated via other processes. For example, there are entire classes of explananda (e.g., the interactions of physical objects) about which we reason via skeletal causal-explanatory frameworks that are conserved across ontogeny or even phylogeny (Spelke \& Kinzler, 2007). Heuristic explanations are more likely in circumstances in which previous knowledge doesn't supply preformulated answers, and thus reasoners would have to engage in effortful processing to construct an answer.
} 
genius-level intelligence posits an inherent fact about them. In contrast, the claim that they are subject to societal stereotypes posits an extrinsic fact about them - a fact that involves entities other than women themselves.

A simple rule of thumb might help readers distinguish between inherent and extrinsic information: Inherent facts are those that, if changed, would lead to a change in the entity itself (Weatherson \& Marshall, 2014). Changing a person's cognitive abilities would induce an actual change in the person him- or herself, but changing cultural stereotypes about the person's group would not. Of course, reasoners need not know this rule of thumb, nor do they need to distinguish between inherent and extrinsic facts while generating explanations. The inherence heuristic claim is not that people purposely select for their explanations inherent facts about the entities in the explanandum. Rather, these facts are unwittingly used to construct heuristic explanations because, we propose, they are so readily retrieved.

We clarify several aspects of the notion of inherence. First, in this work inherence is a psychological, not a metaphysical, construct. Whether or not inherent features truly exist in the world, which is a matter of some debate among philosophers (e.g., Weatherson \& Marshall, 2014), laypeople seem to intuitively conceive of some features as being inherent in the entities that display them. Second, we note that whether a fact is represented as inherent is orthogonal to whether this fact is represented as having inherent or extrinsic origins. For instance, the claim that women are unlikely to possess geniuslevel intelligence says something inherent about women even if this presumed trait was thought to have extrinsic origins (e.g., evolutionary processes). Finally, we note that the inherent/ extrinsic distinction is related - but not reducible - to the common distinction between features and relations (e.g., Gentner \& Kurtz, 2005; Wu \& Barsalou, 2009). Although many inherent facts appeal to features and many extrinsic facts are relational, these two dimensions are dissociable: For instance, inherent claims can involve relations as well (e.g., women are more nurturing than brilliant).

Inherence and accessibility Why might inherent features of the entities in the explanandum be particularly accessible in memory? To begin with, these entities are in the focus of attention when the search for an explanation is triggered, so they are likely to serve as the first, and perhaps only, retrieval cues (e.g., Legrenzi, Girotto, \& Johnson-Laird, 1993; Spiller, 2011; Weber et al., 2007). This attentional spotlight on the entities in the explanandum (e.g., women) may prevent other relevant entities (e.g., the historical and societal context) from coming to mind and may thereby lower the probability of retrieving extrinsic facts that relate the explanandum to phenomena beyond it.

Extrinsic facts may also be slower to come to mind because they tend to be less prominent in our interactions with the relevant entities. For instance, the influence that stereotypes or other societal constraints exert on women's behavior is seldom apparent to a naive observer, resulting in a weaker associative link between such extrinsic factors and the concept woman in semantic memory. Even when they are noticed, extrinsic forces may be more cumbersome to describe in language, whereas inherent ones can often be expressed in a few words (e.g., via generic statements about what the relevant entities are or have, as in "Women aren't brilliant"; e.g., Cimpian, Brandone, \& Gelman, 2010). Any such difference in how complex it is to talk about inherent and extrinsic facts - and thus in how often they are actually talked about - could contribute to an accessibility difference between them.

It is also possible that extrinsic information is less accessible because it tends to involve relations. Information that is more relationally complex is also more difficult to process (e.g., Halford, Wilson, \& Phillips, 1998; Hummel \& Holyoak, 1997) and may therefore be less readily retrieved and incorporated into an explanation. ${ }^{2}$ The tendency to gravitate toward simplicity is, of course, not unique to explanation but rather cuts across many areas of higher-level cognition (e.g., Feldman, 2003; Kahneman, 2011; Pothos \& Chater, 2002).

This accessibility bias favoring the retrieval of inherent information about the entities in the explanandum is in turn hypothesized to constrain the content of the explanations generated. The facts retrieved from memory serve as building blocks for an explanation. Thus, if inherent facts are overrepresented among these building blocks (relative to extrinsic facts that would otherwise be as relevant), it is likely that they will also be overused in the explanations ultimately generated. ${ }^{3}$

To clarify, inherence is distally, rather than proximally, related to accessibility. Inherent facts are accessible because of the specific ways in which they are represented in semantic memory, such as their greater associative relatedness with a target concept, their lower relational complexity, and so on (see foregoing discussion). When these mediating variables are taken into account, inherence may not, in and of itself, explain any unique variance in accessibility. Note, however, that identifying the specific variables that mediate the relationship between inherence and accessibility is beyond the scope of the present work. Our aim here is more modest: to test whether facts that are easily retrieved also tend to be inherent rather than extrinsic, and whether this accessibility difference in turn biases the content of heuristic explanations.

\footnotetext{
${ }^{2}$ If extrinsic facts are more relationally complex, that might also be why they are more difficult to put into words.

${ }^{3}$ The question of how a reasoner determines which of the retrieved facts constitute plausible explanations is outside the scope of the inherence heuristic account, which focuses specifically on the memory and attentional constraints on the process of generating explanations. However, other work provides some insight into this question (e.g., research on explanatory preferences; Lombrozo, 2007) and can be integrated with the inherence heuristic proposal for a more complete account of explanation.
} 
Before describing the four studies we conducted to test these claims, we briefly review some of the prior evidence on the links between memory and explanation.

\section{Prior evidence on the links between memory and explanation}

Memory processes have largely been overlooked in the recent literature on explanation. ${ }^{4}$ The most direct insights into the role of memory processes have come not from the literature on explanation per se, but from the neighboring literature on hypothesis generation. In particular, Thomas, Dougherty, and their colleagues recently proposed a comprehensive model of hypothesis generation (termed HyGene) that covers the various stages of this process, including the retrieval of plausible hypotheses from long-term memory and the evaluation of these hypotheses in working memory (e.g., Thomas, Dougherty, \& Buttaccio, 2014; Thomas, Dougherty, Sprenger, \& Harbison, 2008; see also Mehlhorn, Taatgen, Lebiere, \& Krems, 2011). This elegant framework is compatible in many ways with our proposal of an inherence heuristic in explanation. For instance, the evidence reviewed by Thomas, Dougherty, and colleagues $(2014,2008)$ suggests that people do not perform an exhaustive memory search, but rather retrieve only a small set of hypotheses. In addition, this subset of retrieved hypotheses are those that have been most frequently associated with the explanandum in past experience and are thus most easily activated from long-term memory (e.g., a sore right abdomen was often found to be caused by appendicitis). In other words, HyGene posits that people tend to retrieve those hypotheses that are most accessible.

Although HyGene and the inherence heuristic framework share these basic mechanistic assumptions (i.e., that reasoners rely on a small set of easily retrieved explanatory facts), they also differ in a number of crucial respects. Most importantly, unlike HyGene, the inherence heuristic model makes a claim about the content of the information that is most accessible in memory, proposing that this information often consists of inherent facts about the entities in the explanandum. Moreover, the inherence heuristic model does not assume that reasoners retrieve fully formed hypotheses or explanations from longterm memory. Although this is a reasonable simplification that

\footnotetext{
${ }^{4}$ Some evidence exists on the reverse causal link: namely, the influence of explanations on subsequent memory. In brief, explanations boost memory for the specific aspects of the explananda that are featured in, or otherwise relevant to, the explanations themselves (e.g., Walker, Lombrozo, Legare, \& Gopnik, 2014) - consistent with the depth-of-processing effects widely documented in the literature (e.g., Craik \& Lockhart, 1972). However, explanations also seem to decrease subsequent memory for aspects of the explananda that do not end up being relevant to the formulation of these explanations (e.g., Legare \& Lombrozo, 2014; Walker et al., 2014; Williams \& Lombrozo, 2010).
}

works well when modeling diagnostic reasoning in certain contexts (e.g., medical diagnosis), many of the observations that people seek to explain in everyday life are ones for which they do not have ready-made explanations stored in memory (e.g., why more men than women have been recognized as geniuses). As a consequence, people are often forced to retrieve various facts that may be relevant to an explanation but may not initially constitute an explanation in and of themselves.

In summary, although the HyGene model and the inherence heuristic model share several foundational assumptions about the ways in which memory constrains explanation, they also diverge in a number of equally foundational respects.

\section{The present studies}

The proposal that inherent information is highly accessible in memory, and therefore likely to dominate the content of spontaneous explanations, licensed two specific predictions:

Prediction 1: The facts that come to mind most frequently (Study 1) and most quickly (Study 2) when thinking about an entity are likely to be inherent.

Prediction 2: The facts that are most accessible when constructing an explanation are likely to be inherent facts about the entities in the explanandum (Studies 3 and 4). This will be the case especially when individuals' cognitive resources are taxed (as during much of everyday life), making participants susceptible to heuristic shortcuts (Study 4).

To provide a comprehensive test of these predictions, the stimuli for the present studies were selected from a range of domains (social conventions [Studies 3a and 4], historical events [Study 3b], and scientific phenomena [Study 3c]) and were varied systematically along a number of dimensions (e.g., concreteness [Study 2]).

\section{Study 1}

In Study 1, we investigated the prediction that inherent facts would be frequently called to mind when considering a given entity (Prediction 1). Preliminary evidence for the accessibility of inherent facts can be found in work on concepts and semantic memory-particularly in studies using featurelisting and -verification paradigms. Although none of these prior studies coded features for their inherence (as defined here), a close examination of their materials and results suggests that inherent features tend to be (1) listed often and quickly when people are prompted with a concept (e.g., Ashcraft, 1978; Hampton, 1979, 1981; McRae, Cree, Seidenberg, \& McNorgan, 2005; Rosch, Mervis, Gray, 
Johnson, \& Boyes-Braem, 1976; B. Tversky \& Hemenway, 1984; Vinson \& Vigliocco, 2008; Wu \& Barsalou, 2009) and (2) verified quickly as being true of that concept (e.g., Collins \& Quillian, 1969; Jorgensen \& Kintsch, 1973). However, because these studies did not actually classify features on the basis of whether they were inherent, the support they provide for our prediction is necessarily tentative.

To provide a direct test of the accessibility of inherent information, we used an existing feature-generation dataset (McRae et al., 2005) and tested for a positive relationship between the frequency with which a feature occurred in this dataset and its likelihood of being inherent.

\section{Method}

\section{Participants}

The participants in this and all subsequent studies were recruited online via Amazon's Mechanical Turk platform. Study 1 involved two independent samples of participants: one consisting of 85 participants (41 male, 44 female), and another consisting of 91 participants ( 37 male, 54 female). The procedures were identical across these two samples; only the items differed (see below).

The data totaled 24,880 ratings, which exceeds the typical power recommendations for multilevel models (e.g., Snijders, 2005; West, Ryu, Kwok, \& Cham, 2011). Power simulations for all models were conducted using the SIMR package in $\mathrm{R}$ (Green \& MacLeod, 2016), and each model was determined to have at least $80 \%$ power to detect the predicted effect.

\section{Materials}

To examine whether a fact's accessibility is related to its inherence, we presented our participants with facts from an existing dataset (McRae et al., 2005) and asked them to code these facts as either inherent or noninherent. Importantly, McRae et al. also recorded the frequency of each fact in their dataset (e.g., how often "has keys" was generated for the item accordion), enabling us to examine quantitatively the relationship between accessibility (operationalized as frequency of mentions) and inherence.

McRae et al.'s (2005) dataset This dataset lists the facts that were generated about 514 items, along with the frequency of each fact. Each item was presented to exactly 30 participants, so the maximum frequency was 30 . A fact had to have been produced by at least five participants in order to be included in the dataset, so the minimum frequency was 5 . The elicitation instructions were worded as follows: "On the following pages, there are words that each denote a concept, with each being followed by 14 blank lines. Please fill in as many of these lines as you can with properties of the concept to which the word refers" (p. 556). The participants were then given a few examples of properties they might generate, which included both inherent (e.g., "physical properties") and extrinsic (e.g., "things that the concept is related to," "where it comes from") examples. McRae et al.'s instructions were thus neutral with respect to the inherent-versus-extrinsic dimension.

We randomly sampled two nonoverlapping sets of 100 items (and the facts that accompanied them) from the 514 items in McRae et al.'s dataset and administered them to our two samples of participants. The participants in Samples 1 and 2 rated 1,414 and 1,404 facts, respectively (see the Appendix Table 13 for a list of the items).

\section{Procedure}

The study was administered using the Qualtrics survey platform (Qualtrics, Provo, UT). The procedure consisted of two phases: a training phase and a coding phase.

Training phase Participants first read a definition of inherence ("an inherent feature of an object is one that refers to the object itself, without making reference to external objects or forces, or historical events") and saw several examples of inherent and noninherent facts. Participants were then given four practice trials that required them to decide whether or not a fact was inherent. A "not sure" option was also available, both here and in the coding phase (see below). Two of the practice facts were inherent, and two were noninherent. After each practice trial, participants saw the correct answer as well as the rationale for it. Participants who did not code the last two practice facts correctly ("used in Nike campaigns" [noninherent] and "is round" [inherent] about a soccer ball) were omitted from further analyses. Fourteen participants (beyond those reported above) were excluded on the basis of this criterion in Sample 1, and ten in Sample 2.

Coding phase After training, each participant was presented with ten items randomly selected from the set of 100 we had pulled from McRae et al.'s (2005) dataset. Participants coded all facts that accompanied those ten items as inherent or noninherent, without receiving any feedback. The order of the features was randomized. To ease the memory load, we reiterated on each trial what is meant by an inherent feature. Each item's facts were coded by $6-11$ participants (medians = 8 in Sample 1 and 9 in Sample 2).

\footnotetext{
${ }^{5}$ No significant results became nonsignificant when we included these participants in our analyses. In fact, the results with and without these participants were nearly identical.
} 
Analytic strategy

In all studies, the data were analyzed with mixed-effects models using the lme4 package in R (Bates, 2007). Unless otherwise noted, these mixed-effects models included random intercepts and slopes for both items and subjects. Also, because no analytical (i.e., precise) methods exist for calculating degrees of freedom - and thus $p$ values - for mixed-effects models (Bates, Mächler, Bolker, \& Walker, 2014), we bootstrapped 95\% confidence intervals (CIs) for all our coefficients and used whether these CIs crossed 0 to determine significance.

\section{Open data and analytic syntax}

The raw data and analytic syntax for this and all subsequent studies are available on the Open Science Framework (https:// o s f. i o / p j u 7 r / ? v i e w o n 1 y = ad8fla0e51524ffaa5cf0553093c977f).

\section{Results and discussion}

\section{Sample 1}

Participants judged $59.5 \%$ of the facts to be inherent and $36.1 \%$ to be noninherent. The predominance of inherent facts is broadly consistent with our claim that such facts are easily accessible. Also of interest, participants were seldom unsure of how to code a fact (4.4\% of cases). Agreement among participants was high: On average, $80.5 \%$ of participants agreed about whether or not a fact was inherent, despite the minimal instructions.

To test our first prediction - that frequently generated facts are likely to be inherent-we modeled whether a fact was judged as inherent on the basis of the frequency with which it occurred in McRae et al.'s (2005) dataset (range = 5 to 30; median =9). As predicted, facts that occurred more often in McRae et al.'s dataset were also significantly more likely to be judged as inherent by the participants in our study, $b=0.03, S E$ $=0.01$, bootstrapped 95\% CI: [0.01, 0.05] (see Table 1 for the full model). Concretely, this result indicated that, with each additional mention by McRae et al.'s participants, a fact's odds of being judged as inherent (vs. noninherent) increased by $3.0 \%$. Alternatively, a $1 S D$ increase in frequency was accompanied by a $16.7 \%$ increase in the odds of being judged as inherent.

\section{Sample 2}

Participants judged $56.8 \%$ of the facts in the second set of 100 items to be inherent and $39.6 \%$ to be noninherent, choosing "not sure" in only $3.6 \%$ of cases. Agreement across participants was also high: On average, $80.4 \%$ of participants agreed on whether a fact was inherent or not.
Importantly, as in the first sample, facts that had been generated more frequently in McRae et al.'s (2005) dataset were significantly more likely to be coded as inherent by our participants, $b=0.05, S E=$ 0.01, bootstrapped 95\% CI: [0.03, 0.07] (see Table 2 for the full model). With each additional mention, a fact's odds of being coded as inherent (vs. noninherent) increased by $5.4 \%$. Or, to use a different metric, a $1 S D$ increase in the frequency of mentions was accompanied by a $30.9 \%$ increase in a fact's odds of being coded as inherent.

In summary, the results of Study 1 provide support for our first prediction - that when thinking about an entity, the facts that come to mind most frequently are likely to be inherent.

\section{Study 2}

In Study 2, we tested whether the features that are retrieved earliest when thinking about an entity - a different operationalization of accessibility - are likely to be inherent (Prediction 1). That is, do people typically retrieve inherent facts before noninherent facts?

A second goal of this study was to expand the range of items beyond the concrete physical objects that made up McRae et al.'s (2005) dataset. This greater diversity of items (e.g., wedding, breakfast; see the Appendix Table 13) allowed us to provide a more general test of the claim that inherent information is easily accessible in memory: Are inherent facts accessible only for concrete items like those in Study 1, or does the relationship between inherence and accessibility hold regardless of the concreteness of the entities participants are reasoning about?

\section{Method}

Participants The participants were 111 Mechanical Turk workers (60 female, 48 male, and three who did not indicate a gender). Two additional participants were tested but excluded for failing to complete the task (see below).

Materials and procedure McRae et al.'s (2005) dataset does not include information about the order in which facts were retrieved. Because we could not rely on this dataset to test the present prediction, we collected our own retrieval data. Participants were presented with 15 items (randomly ordered; see the Appendix Table 13 for a list) and were asked to write "all of the facts that first come to mind" about each. The instructions were purposely neutral and unconstrained, to avoid biasing participants' productions. Participants typed their responses on 20 blank lines, one fact per line. The key measure in this study was the ordinal position of each fact in this list, which we used as a predictor of the fact's inherence rating: Facts closer to the top of the list (i.e., those generated quickly) should be more inherent than facts generated later. To ensure that a fact's position on the list mapped straightforwardly onto 
Table 1 Mixed-effects logistic regression predicting the likelihood that a fact is inherent, based on the frequency with which it was produced in McRae et al.'s (2005) dataset (Study 1, Sample 1)

\begin{tabular}{llll}
\hline $\begin{array}{l}\text { Fixed Effects } \\
\text { Intercept) }\end{array}$ & Estimate & SE & Bootstrapped 95\% CI \\
Frequency & 0.13 & 0.12 & -0.12 \\
& 0.03 & 0.01 & 0.01 \\
Random Effects & Predictor Variable & & $S D$ \\
Grouping variable: Subject & & Intercept & 0.50 \\
& Frequency & Slope & 0.01 \\
Grouping variable: Item & & Intercept & 0.94 \\
& Frequency & Slope & 0.09 \\
\hline
\end{tabular}

Observations: 12,043; Subjects: 86; Items: 100

its ease of retrieval, we sought to prevent participants from reordering their responses after generating them. Such reordering was minimized by (1) giving participants a limited amount of time to make their responses and (2) introducing some unpredictability in the duration of each trial. Specifically, we randomly varied whether participants could spend 20, 25, or $30 \mathrm{~s}$ on each item. Participants who skipped more than one-third of the items were excluded $(n=2)$.

Coding The coding scheme was similar to that provided to the participants in Study 1. However, we asked trained researchers to code the 8,444 facts generated in the present study rather than relying on Mechanical Turk workers. The production data in Study 2 were completely unfiltered and unprocessed - and thus much less tidy than McRae et al.'s (2005) dataset. The facts generated by McRae et al.'s participants underwent considerable cleaning and processing before inclusion in their dataset, which made it feasible to ask our naive participants in Study 1 to code them. This was not a viable option here. For the same reason, we also used trained coders in Study 4.

All facts were coded for inherence by the first author (without knowledge of the order in which the facts had been generated), and a subset $(25 \%)$ were also coded by a research assistant blind to both fact order and the hypothesis. The intercoder agreement was $81.2 \%$.

Although we used researchers' codes as the dependent variable in our analyses, we also wanted to explore whether untrained Mechanical Turk workers' ratings of these unfiltered production data would nevertheless converge with the researchers' ratings. To do so, we recruited an additional sample of 27 Mechanical Turk workers and asked them to code a random subset of the 8,444 facts generated in this study; this subset consisted of 509 facts, which all 27 participants rated. To assess agreement with the researchers, we conducted a mixed-effects logistic regression predicting the researchers' rating of a fact (as inherent vs. not inherent) on the basis of whether the 27 Mechanical Turk workers coded it as inherent. This analysis revealed a significant and strong positive relationship, $b=1.62, S E=0.23$, bootstrapped $95 \% \mathrm{CI}$ : [1.18, 2.08]. More concretely, if a Mechanical Turk participant rated a fact as inherent, that increased its odds of being rated as inherent by the researchers by $406 \%$. This result suggests, again, substantial convergence among the raters-trained and untrained - in their codings of inherence.

Concreteness ratings To test whether the relationship between inherence and memory accessibility differed as a

Table 2 Mixed-effects logistic regression predicting the likelihood that a fact is inherent, based on the frequency with which it was produced in McRae et al.'s (2005) dataset (Study 1, Sample 2)

\begin{tabular}{clll}
\hline $\begin{array}{l}\text { Fixed Effects } \\
\text { (Intercept) }\end{array}$ & Estimate & SE & Bootstrapped 95\% CI \\
Frequency & -0.22 & 0.12 & -0.45 \\
& 0.05 & 0.01 & 0.03 \\
Random Effects & Predictor Variable & & $S D$ \\
Grouping variable: Subject & & Intercept & 0.06 \\
& Frequency & Slope & 0.001 \\
Grouping variable: Item & & Intercept & 0.91 \\
& Frequency & Slope & 0.07 \\
\hline
\end{tabular}

Observations: 12,837; Subjects: 91; Items: 100 
function of the concreteness of the items, we asked a separate group of Mechanical Turk participants $(n=25)$ to rate the concreteness of the 15 items used in this study on a 7-point scale (from $1=$ least concrete to $7=$ most concrete). Participants were instructed to rate an item as concrete to the extent that it could be "seen, heard, felt, smelled, or tasted" (adapted from Paivio, Yuille, \& Madigan, 1968; Spreen \& Schulz, 1966). The average rating for each item (range = 2.24 to 6.68 ) was included as a predictor in our main analysis.

\section{Results and discussion}

Participants generated a total of 8,444 facts. The percentage of inherent facts, computed over the entire dataset, was $47.1 \%$. Although this number is lower than in Study 1, it is worth noting that participants' production was completely unconstrained in this study - they were asked to report "all of the facts that first come to mind." These instructions resulted in a fair number of responses that were simply idiosyncratic associations with the target concept (e.g., "33 Cheshire" for the concept house; "I hate end pieces" for the concept bread). (Because McRae et al.'s, 2005, dataset included only features generated by at least five individuals, it automatically excluded idiosyncratic responses.) When we coded these responses and removed them from the present data, leaving 6,710 facts, the percentage of inherent facts resembled that in Study 1: 59.3\%.

Our main prediction in this study was that the facts that come to mind first are likely to be inherent. To test this prediction, we conducted a mixed-effects logistic regression in which we modeled whether a fact is inherent on the basis of the ordinal position at which it was produced. We expected that facts closer to the top of the list (and thus generated earlier) would be more likely to be inherent than facts at the bottom. This model included two additional predictors: each item's concreteness rating, and the interaction between this concreteness rating and the ordinal position of the facts generated about each item. The interaction term allowed us to test whether the hypothesized relationship between the ordinal position (i.e., the accessibility) of a fact and its inherence was moderated by the concreteness of the entity serving as a memory prompt. Both the intercept and the slope of the relation between ordinal position and inherence were allowed to vary randomly across items and across subjects. All predictors were mean-centered to facilitate interpretation of their coefficients. This model included all 8,444 facts (without excluding idiosyncratic responses).

As predicted, we found a significant relationship between ordinal position and inherence, such that earlier-generated facts were more likely to be inherent than later-generated ones, $b=$ $-.09, S E=.04$, bootstrapped 95\% CI: [-.15, -.003] (see Table 3 for the full model). In concrete terms, a one-place shift toward an earlier position (e.g., from being the third fact generated to being the second) corresponded to an $8.2 \%$ increase in the odds that a fact was inherent. The relationship between ordinal position and inherence was not significantly moderated by the concreteness of the items being considered, $b=.05, S E=.03$, bootstrapped $95 \% \mathrm{CI}$ : [-.01, .09]. This nonsignificant interaction suggests that inherent features are among the first to come to mind, whether one is reasoning about concrete items such as a lion or relatively abstract items such as a language. However, this study included a relatively small number of items (15); future work with a broader range of concrete and abstract items would bolster confidence in this conclusion.

Taken together, the results from Studies 1 and 2 provide evidence that inherent facts and features are generated (a) more frequently and (b) earlier than noninherent facts when thinking about an entity.

\section{Study 3a}

The results so far lend support to the claim that inherent information is highly accessible in memory. In Study 3 we investigated the accessibility of inherent information during explanation (Prediction 2). That is, we asked whether the inherent information that comes to mind quickly when people consider various entities is also likely to be used in their explanations for phenomena involving these entities. The participants in Study 3a were asked several "why?" questions (e.g., "Why is white the most popular color of new cars?") and were allowed to think about each for a few seconds; the brevity of the delay was intended to mimic the conditions under which most everyday explanations would be generated. After each question, participants rated a series of inherent and noninherent facts for their similarity to the facts that had come to mind when considering the "why?" question (which is how accessibility was operationalized in this study). We predicted that a fact's inherence would be positively related to its accessibility during explanation, even when adjusting for the fact's plausibility as an explanation. That is, inherent facts should be rated as more similar to the content retrieved from memory relative to extrinsic facts of equal plausibility as explanations.

\section{Method}

Participants, materials, and procedure The participants $(N$ $=100 ; 52$ male, 48 female) in Study 3 were asked to consider six "why?" questions (e.g., "Why is white the most popular color of new cars?"). In this study, all questions concerned familiar societal patterns (see Table 4). We asked about patterns for which most participants would have to construct an explanation on the spot rather than simply being able to retrieve previously learned explanations. (Heuristic processing is only invoked when the reasoner is confronted with difficult questions - not with questions that have rehearsed, familiar answers.) Each question was displayed for $10 \mathrm{~s}$, during which participants were instructed to "consider the following 
Table 3 Mixed-effects logistic regression predicting the likelihood that a fact is inherent, based on its ordinal position in participants' production, the concreteness of the entity the fact is about, and the interaction of these two variables (Study 2)

\begin{tabular}{|c|c|c|c|c|}
\hline Fixed Effects & Estimate & $S E$ & \multicolumn{2}{|c|}{ Bootstrapped 95\% CI } \\
\hline (Intercept) & -0.14 & 0.21 & -0.54 & 0.20 \\
\hline Ordinal Position & -0.09 & 0.04 & -0.15 & -0.003 \\
\hline Concreteness & -0.26 & 0.14 & -0.56 & 0.03 \\
\hline Ordinal Position $\times$ Concreteness & 0.05 & 0.03 & -0.01 & 0.09 \\
\hline Random Effects & Predictor Variable & & $S D$ & \\
\hline \multirow[t]{2}{*}{ Grouping variable: Subject } & & Intercept & 0.41 & \\
\hline & Ordinal Pos. & Slope & 0.10 & \\
\hline \multirow[t]{2}{*}{ Grouping variable: Item } & & Intercept & 0.77 & \\
\hline & Ordinal Pos. & Slope & 0.13 & \\
\hline
\end{tabular}

Observations: 8,444; Subjects: 111; Items: 15

question and what sorts of information might be relevant to answering it." After $10 \mathrm{~s}$, participants were presented with six facts (e.g., "White is neutral") and were asked to indicate how similar each fact was to the information that had come to mind when they considered the "why?" question on their own. Table 4 contains a full list of the questions and the explanatory facts used in this study.

Inherence ratings A separate group of participants $(n=47)$ were asked to rate the facts in the main task ( 6 questions $\times 6$ facts $=36$ facts total) on whether they described inherent features of the entities in the relevant "why?" questions (7-point scale, with $1=$ not inherent and $7=$ inherent). The facts were rated as spanning the range from clearly noninherent to clearly inherent (range $=1.47$ to 6.62 ; see Table 4 ).

Plausibility ratings Another set of ratings was collected to ensure that any relationship we might find between inherence and accessibility was not driven simply by differences in the plausibility of the inherent and extrinsic facts as potential explanations (i.e., that the inherent facts we happened to choose don't provide more plausible or satisfying explanations than extrinsic facts). A separate group of participants $(n=50)$ were asked to rate the plausibility of each fact as a potential explanation for the associated "why?" question. Plausibility ratings were recorded on 7-point scales (with $1=$ extremely implausible and $7=e x$ tremely plausible) and were included as a control variable in our main analyses (see Table 4 for the plausibility ratings of all 36 facts). Adjusting for this variable allowed us to test whether the inherence of a fact makes a unique contribution to its accessibility when generating explanations, above and beyond the fact's plausibility as an explanation.

\section{Results and discussion}

To investigate the relation between a fact's inherence and its accessibility in memory during explanation, we conducted a linear mixed-effects regression using the lmer command in $\mathrm{R}$ (Bates, 2007). Specifically, we modeled each fact's accessibility (i.e., its similarity to what came to participants' minds) as a function of (1) its inherence (a continuous variable), which was our main independent variable, and (2) its plausibility (also continuous), which served as a control variable. Intercept and slope random effects were allowed for the inherence variable across items and subjects.

As predicted, we found a significant positive relationship between the inherence of the presented facts and their accessibility during explanation, even when controlling for their explanatory plausibility, $b=0.16, S E=0.04$, bootstrapped $95 \%$ CI: $[0.07,0.24]$ (see Table 5). ${ }^{6}$ Building on the results of Studies 1 and 2, these findings suggest that inherent information is readily accessed when generating in-the-moment explanations, which in turn skews the content of the explanations generated. When participants considered "why?" questions about various commonplace facts, inherent information about the entities in the explanandum was more likely to come to mind than was equally plausible extrinsic information.

\section{Study 3b}

To test the generality of the bias toward inherence in retrieval during explaining, we expanded the range of explananda to include historical events (Study 3b) and scientific phenomena (Study 3c).

\section{Method}

Participants and materials As in Study 3a, the participants here ( $N=100 ; 40$ male, 60 female) were asked to think about six "why?" questions, except this time the questions

\footnotetext{
${ }^{6}$ Inherence was also positively related to accessibility in a model that did not adjust for plausibility, $b=0.26, S E=0.05$, bootstrapped 95\% CI: $[0.15,0.35]$.
} 
Table 4 The stimuli used in Study 3a, with their inherence and plausibility ratings (on 1-7 scales)

\begin{tabular}{|c|c|c|}
\hline "Why?" Questions and Associated Facts & Inherence & Plausibility \\
\hline \multicolumn{3}{|l|}{ Question: Why do people eat eggs most often for breakfast (and not lunch, or dinner)? } \\
\hline -Eggs are high in protein & 6.55 & 5.60 \\
\hline -Eggs tend to be filling & 6.13 & 5.28 \\
\hline -Eggs can be eaten in a variety of forms & 5.34 & 5.52 \\
\hline -Eggs are on the breakfast menu in many restaurants & 2.23 & 5.72 \\
\hline -Even people who have little experience with cooking or who are in a hurry can prepare eggs & 1.85 & 5.38 \\
\hline -Eggs don’t require many utensils or appliances to prepare & 3.70 & 4.68 \\
\hline \multicolumn{3}{|l|}{ Question: Why are boys good at soccer? } \\
\hline -Soccer is a sport that requires a lot of strength and endurance & 5.57 & 5.22 \\
\hline -Boys have lots of energy & 5.44 & 5.48 \\
\hline -Boys are competitive and aggressive & 5.49 & 5.36 \\
\hline -Soccer practice is a typical after-school activity for boys & 3.21 & 5.34 \\
\hline -On the playground, boys have lots of opportunities to play soccer and improve their skills & 2.85 & 5.20 \\
\hline -Parents often feel that boys should play a sport & 2.11 & 5.44 \\
\hline \multicolumn{3}{|l|}{ Question: Why is white the most popular color of new cars? } \\
\hline -White is neutral & 6.40 & 5.58 \\
\hline -White is bright and easy to see & 6.62 & 5.36 \\
\hline -White reflects sunlight and keeps cars cool & 6.36 & 5.62 \\
\hline -Lots of historical and marketing trends go into making a particular color popular & 1.47 & 4.72 \\
\hline -Car manufacturers offer discounts on certain colors & 2.06 & 4.34 \\
\hline -Car commercials influence color choices & 2.11 & 5.22 \\
\hline \multicolumn{3}{|l|}{ Question: Why is the piano one of the most common instruments for young children to play? } \\
\hline -It's fairly easy to generate music on a piano & 5.21 & 5.16 \\
\hline -You can play several children's songs with only a few notes on a piano & 4.06 & 5.40 \\
\hline -Children's small hands can still generate music on a piano & 4.64 & 5.06 \\
\hline -Pianos and keyboards are fairly easy to find and come in a wide range of prices & 3.47 & 5.20 \\
\hline -In-home piano lessons are convenient for busy parents & 2.55 & 5.00 \\
\hline -For parents, asking children to practice the piano is a way to keep them occupied for long periods of time & 2.11 & 4.18 \\
\hline \multicolumn{3}{|l|}{ Question: Why are dogs the most common house pets for young children? } \\
\hline -Children need pets as energetic as they are & 3.34 & 4.80 \\
\hline -Dogs can be trained easily & 6.02 & 5.32 \\
\hline -Dogs tend to be friendly and social & 6.23 & 6.18 \\
\hline -Parents see dogs as a way to teach children responsibility & 2.36 & 5.60 \\
\hline -Children want to be like their friends, and many families already have dogs as pets & 2.28 & 4.82 \\
\hline -Children see dogs as pets in their neighborhoods and on television & 2.09 & 5.32 \\
\hline \multicolumn{3}{|l|}{ Question: Why do a large percentage of workers eat their lunch at their desk, instead of going out? } \\
\hline -Eating lunch at one's desk allows one to get more done & 4.06 & 5.40 \\
\hline -Lunch often consists of some very simple food — something like a sandwich or a salad & 5.30 & 4.86 \\
\hline -Eating lunch typically takes only a few min & 4.55 & 4.96 \\
\hline -Bosses may frown on leaving work & 2.02 & 4.80 \\
\hline -Working through lunch makes a good impression with one's employer & 2.34 & 4.92 \\
\hline -Employers give short lunch breaks, which may not allow time to go out & 3.13 & 5.94 \\
\hline
\end{tabular}

referenced historical events (e.g., "Why was Ancient China the birthplace of many key inventions [like gunpowder and paper]?"; see Table 6 for a full list of the items). As in Study $3 \mathrm{a}$, we asked about events for which participants would not already have an explanation and for which they would thus have to construct one in the moment. Note that asking participants to explain historical events provided a conservative test of our hypothesis, since such events are often explained (e.g., in textbooks or documentaries) by pointing to some set of precipitating circumstances (i.e., extrinsic factors). 
Table 5 Linear mixed-effects model predicting the similarity of presented facts to what came to mind when considering "why?" questions about societal patterns (Study 3a)

\begin{tabular}{llll}
\hline Fixed Effects & Estimate & $S E$ & Bootstrapped 95\% CI \\
(Intercept) & -1.71 & 0.47 & -2.46 \\
Plausibility of fact & 1.02 & 0.09 & 0.85 \\
Inherence of fact & 0.16 & 0.04 & 0.07 \\
Random Effects & Predictor Variable & & $S D$ \\
Grouping variable: Subject & & Intercept & 1.27 \\
Grouping variable: Item & Inherence & Slope & 0.21 \\
& & Intercept & 0.35 \\
\hline
\end{tabular}

Observations: 3,600; Subjects: 100; Items: 6

Procedure The procedure was identical to that of Study 3a, with two exceptions. Participants were given $20 \mathrm{~s}$ to think about each question (rather than $10 \mathrm{~s}$, as in Study 3a). We allowed the extra time because the explananda used in this study were somewhat more complex than those in Study 3a. Second, we elicited inherence and plausibility ratings from the same participants that had completed the main task (rather than from separate groups of participants, as in Study 3a). The inherence and plausibility rating tasks were presented after the main task, in random order.

\section{Results and discussion}

A linear mixed-effects regression analogous to that in Study 3a replicated the main result of that study: The inherence of a fact positively predicted its accessibility in the service of explanation, above and beyond its plausibility, $b=0.06, S E=$ 0.03, bootstrapped 95\% CI: $[0.003,0.11]$ (see Table 7 for the full results). ${ }^{7}$ Thus, inherent information comes to mind more easily than equally relevant extrinsic information even when people have to generate explanations about historical events, which are arguably a very different type of explanandum than the everyday facts used in Study $3 \mathrm{a}$ (e.g., that white is the most popular color of cars). ${ }^{8}$

\section{Study 3c}

In Study 3c, we further broadened the scope of our test of the inherence heuristic by exploring whether inherent information

\footnotetext{
${ }^{7}$ Inherence was also positively related to accessibility in a model that did not adjust for plausibility, $b=0.11, S E=0.04$, bootstrapped 95\% CI: [0.03, 0.20].

${ }^{8}$ The magnitude of the relationship between inherence and accessibility was attenuated in this study relative to Study $3 \mathrm{a}$. One possible reason for the weaker relationship is our use of historical events as explananda. However, it is important to also keep in mind that participants were given twice as long as in Study $3 \mathrm{a}$ to think about each question ( $20 \mathrm{vs}$. $10 \mathrm{~s}$ ). The more time people spend retrieving information from memory, the more likely they may be to retrieve less-accessible extrinsic information (see Study 4 for empirical evidence on this point), which might also explain why inherent information was not as dominant in participants' retrieval in this study.
}

is also accessible when participants are explaining unfamiliar scientific phenomena.

\section{Method}

Participants, materials, and procedure The 101 participants (34 male, 67 female) were asked to think about six "why?" questions about phenomena from chemistry, physics, and biology (e.g., "Why did a piece of manganese [a mineral element] weigh more when exposed to heat?"; see Table 8 for the full list of items). As before, these explananda were chosen so that participants had to construct an explanation for them rather than simply retrieve a previously formed one. Aside from the explananda used, the study was identical to Study $3 b$.

\section{Results and discussion}

As in Studies 3a and 3b, we conducted a linear mixedeffects regression predicting a fact's accessibility for explanation (i.e., its similarity to what came to mind while considering the relevant "why?" question), on the basis of its inherence and its plausibility as an explanation. The results revealed-for a third time-that inherence was a significant predictor of accessibility for explanation above and beyond plausibility, $b=0.10, S E=0.03$, bootstrapped 95\% CI: [0.03, 0.15] (see Table 9 for the full results). ${ }^{9}$

Together, the results from Studies $3 a-3 c$ suggest that, across a wide range of explananda, inherent information is more accessible when people construct explanations than is extrinsic information of equal relevance to the explanation. However, this evidence is somewhat indirect, in that we did not actually elicit and code the explanations that participants generated in response to our "why?" questions. Rating the similarity of self- and experimenter-

\footnotetext{
${ }^{9}$ Inherence was also positively related to accessibility in a model that did not adjust for plausibility, $b=0.20, S E=0.03$, bootstrapped 95\% CI: $[0.14,0.26]$.
} 
Table 6 The stimuli used in Study 3b, with their inherence and plausibility ratings (on 1-7 scales)

"Why?" Questions and Associated Facts $\quad$ Inherence Plausibility

Question: Why was chocolate (rather than other foods) a popular delicacy in medieval Europe?

-Chocolate has a rich and robust flavor

6.40

6.26

5.54

-Chocolate keeps well without refrigeration

-Sugar and spices were imports from the New World

-The Aztecs shared chocolate with European explorers

-European countries had colonies in tropical regions

Question: Why did the Mali Empire (in 14th-century West Africa) achieve the success it did?

-The Empire had a strong standing army

-The Empire had a strong economy

-The Empire had good leadership

-The location of the Empire was favorable

-The Empire's neighbors were weak

-The Sahara protected the Empire from invaders

Question: Why was the kingdom of Hawaii overthrown (at the end of the 19th century)?

-Hawaii's economy was weak and unstable

-Hawaii's monarchs were unpopular

-Hawaii's different islands were feuding with one another

-Monarchies all over the world were being overthrown at this time

-Pearl Harbor was strategically important for the U.S.

-The U.S. was trying to expand its territory

Question: Why did the U.S. purchase Alaska from the Russian empire?

-Alaska is rich in natural resources, including timber and oil

-Alaska has a large territory

-Alaska has beautiful scenery

-Alaska connects North America and Asia

-It was a political move

-Alaska has strategic importance

Question: Why did the city of Angkor (the capital of the Khmer empire in the 1400s) fall?

-Angkor had an unstable and inefficient government

-Angkor had a poorly trained army

-Angkor's outer walls were thin and insufficient to protect it

-Its attackers were powerful

-Plagues and natural disasters weakened Angkor's defenses

-Angkor's location was too exposed

Question: Why was Ancient China the birthplace of many key inventions (like gunpowder and paper)?

-Ancient China valued scholarship and invested a lot in education

generated explanations is one step removed from the processes involved in generating explanations. In addition, one may argue that the extrinsic facts relevant to the "why?" questions asked in Study 3 were more numerous and more diverse than the relevant inherent facts. If the space of possible extrinsic explanations was indeed larger, 
Table 7 Linear mixed-effects model predicting the similarity of presented facts to what came to mind when considering "why?" questions about historical events (Study 3b)

\begin{tabular}{llll}
\hline $\begin{array}{l}\text { Fixed Effects } \\
\text { (Intercept) }\end{array}$ & Estimate & $S E$ & Bootstrapped 95\% CI \\
Plausibility of fact & 0.91 & 0.19 & 0.53 \\
Inherence of fact & 0.55 & 0.02 & 0.51 \\
& 0.06 & 0.03 & 0.003 \\
Random Effects & Predictor Variable & & $S D$ \\
Grouping variable: Subject & & Intercept & 0.91 \\
& Inherence & Slope & 0.10 \\
Grouping variable: Item & & Intercept & 0.26 \\
& Inherence & Slope & 0.06 \\
\hline
\end{tabular}

Observations: 3,600; Subjects: 100; Items: 6

this might explain in part why the experimenter-generated extrinsic facts were dissimilar to what came to participants' minds. These limitations are addressed in Study 4.

\section{Study 4}

In the final study, we tested our claim concerning the accessibility of inherent information during explanation (Prediction 2) by examining the content of participants' actual explanations. The logic of this test was as follows: If inherent information comes to mind most readily, as we propose, then the retrieval advantage for inherent (over noninherent) information should be most pronounced when participants have limited time and cognitive resources to generate an explanation. Arguably, these are the circumstances under which explanations are typically generated in everyday life - at a quick pace, without the luxury of putting ongoing activity on hold to carefully consider an answer. If ample time is made available, however, the heuristic processing that is otherwise typical might give way to more analytic, Type 2 processes (see, e.g., Evans \& Stanovich, 2013). Under these circumstances, extrinsic information might actually be retrieved and integrated into participants' explanations, lessening the inherence bias in the content of these judgments.

Thus, in Study 4 we asked participants to generate explanations either under a time limit (speeded condition) or under no such limit (nonspeeded condition). We predicted that the explanations generated under time pressure would rely on inherent information, which is easily accessible, more heavily than would the explanations generated with no time constraints, which we predicted would show less of an imbalance between inherent and extrinsic information.

\section{Method}

Participants, materials, and procedure All participants $(N=$ 202; 87 male, 115 female) were asked to generate ten explanations for familiar societal patterns similar to those in Study 3a (e.g., "Why are wallets generally made of leather instead of other materials (e.g., rubber or canvas)?"; for a full list of the explanation prompts, see Table 10). However, the circumstances under which they generated the explanations differed depending on the condition to which they had been randomly assigned. To capture the constraints under which explanations are often generated outside the lab, the participants in the speeded condition $(n=99)$ were asked to "answer as quickly as possible," and the survey software advanced automatically to the next trial after $15 \mathrm{~s}$. In contrast, the participants in the nonspeeded condition ( $n=103$ ) were told that they would have "as much time as [they] need to answer each question" and that they should "answer as carefully as possible." The slower time course was hypothesized to afford analytic, reflective processes - which are themselves slower and more resource-intensive - more of an opportunity than they would ordinarily have to influence the content of the explanations generated.

In both conditions, we also recorded the number of seconds that participants spent coming up with their explanations. These data were used to test two further predictions concerning the relationship between memory accessibility and explanation content: If extrinsic information is relatively harder to access in memory, then the probability that an explanation contained such information should increase with the latency of the explanation. In contrast, if inherent information is highly accessible, it should be present in participants' explanations regardless of the latency with which these explanations were generated.

Coding Depending on the information they referenced, explanations were coded into three categories, which were not mutually exclusive: "inherent," "extrinsic," and "other" (which included "don't know" responses, nonsensical explanations, etc.). If an explanation contained inherent facts about the entities in the explanandum (e.g., "leather is durable and can withstand the regular bending"), it received a 1 for the "inherent" 
Table 8 The stimuli used in Study 3c, with their inherence and plausibility ratings (on 1-7 scales)

"Why?" Questions and Associated Facts Inherence Plausibility

Question: Why can the Impatiens grandisepala plant, which is found on the slopes of Mount Cameroon, flourish without exposure to nearly any sunlight?

-It is very efficient in its use of light to generate food/energy

$5.64 \quad 6.26$

-It can generate food/energy in other ways

-It can survive with less food/energy than other plants

-The sunlight at higher elevations is more powerful

-The soil is richer there

Question: Why does solid sediment appear after distilled water has been boiled for 100 days in a sealed container?

-The boiling over time changes the chemical structure of the water

-Water contains microscopic particles and chemicals

-The water evaporates over time and leaves behind whatever non-water substances were in it

-The steam caused the container to start breaking down

-The container wasn't made for long-term heat exposure

-The damp environment led mold and fungi to grow at the bottom of the vessel

Question: Why did a cannonball that was fired at a target 1000 meters north curve to the right of the target?

-The cannonball was somehow defective

-The cannonball spun to the right when it was released

-The cannonball was not the right size or composition

-The curvature of the Earth influenced the trajectory

-Strong winds moved the cannonball in the air

Question: Why did bits of pollen that had been in storage for months start moving around rapidly when placed in water?

-The chemical structure of the pollen led it to move when exposed to water

-The pollen was re-animated by exposure to water

-The pollen granules are very small and light

-Water molecules collided with the pollen and created random motion

-There were microorganisms in the water

-A current of air in the room caused the motion

Question: Why does the wild Siberian Nyctereutes dog maintain one life-long mate, while most other wild dogs have multiple mates over the course of their lives?

-Both parents are very involved in raising the pups

-The Nyctereutes only give birth to one litter

-The Nyctereutes form strong emotional attachments, like domesticated dogs

-Living in Siberia makes it hard to travel far and find multiple mates

-The Nyctereutes live in small groups

Question: Why did a piece of manganese (a mineral element) weigh more when exposed to heat?

-The manganese atoms fused into heavier elements when heated

-The heat caused a chemical reaction within the manganese that made it more dense and heavy

category and a 0 otherwise. If an explanation made mention of extrinsic (i.e., environmental, historical, or contextual) information (e.g., "tradition; cow hide was plentiful and easy to process"), it received a 1 for the "extrinsic" category and a 0 
Table 9 Linear mixed-effects model predicting the similarity of presented facts to what came to mind when considering "why?" questions about scientific phenomena (Study 3c)

\begin{tabular}{llll}
\hline $\begin{array}{l}\text { Fixed Effects } \\
\text { (Intercept) }\end{array}$ & Estimate & $S E$ & Bootstrapped 95\% CI \\
Plausibility of fact & 0.97 & 0.17 & 0.62 \\
Inherence of fact & 0.51 & 0.02 & 0.47 \\
& 0.10 & 0.03 & 0.03 \\
Random Effects & Predictor Variable & & $S D$ \\
Grouping variable: Subject & & Intercept & 0.99 \\
& Inherence & Slope & 0.06 \\
Grouping variable: Item & & Intercept & 0.25 \\
& Inherence & Slope & 0.06 \\
\hline
\end{tabular}

Observations: 3,635; Subjects: 101; Items: 6

otherwise. Explanations that contained both inherent and extrinsic information received a 1 for both the "inherent" and "extrinsic" categories. The explanations were coded by the first author, who was blind to the condition they came from, as well as by a research assistant who was blind to both condition and the hypothesis under investigation. The intercoder agreement was $83.7 \%$. Disagreements were resolved via discussion.

As in Study 2, we also wanted to explore whether untrained Mechanical Turk workers' ratings of these explanations would converge with the researchers' ratings. Thus, we recruited an additional sample of 20 Mechanical Turk workers and asked them to code a random subset of 100 explanations generated by the participants in the main study (ten explanations for each of the ten items). These coders were given minimal instruction similar to that provided to the participants in Study 1, except that the instructions focused on determining whether an explanation, as opposed to a feature, is inherent versus extrinsic. To assess agreement with the researchers, we conducted a mixed-effects logistic regression predicting how researchers coded an explanation on the basis of how the Mechanical Turk workers coded it.

Table 10 The "why?" questions used in Study 4

Why are most table settings (e.g., plates, bowls, glasses) made of glass? Why do women tend to have long hair?

Why is spring, as opposed to other seasons (e.g., fall), the most popular time for weddings?

Why do engagement rings have diamonds?

Why do birthday cakes have candles, as opposed to other decorations (e.g., flowers)?

Why is toothpaste typically flavored with mint, instead of other flavors (e.g., cinnamon)?

Why are wallets generally made of leather instead of other materials (e.g., rubber or canvas)?

Why do movie theatres most often sell popcorn, as opposed to other snacks (e.g., pretzels)?

Why are most cars painted a single, solid color (as opposed to being patterned or displaying an image)?

Why are hot dogs commonly sold at sporting events?
This analysis revealed a strong positive relationship between the two sets of codes, $b=1.20, S E=0.24$, bootstrapped $95 \% \mathrm{CI}$ : $[0.68,1.70]$. To illustrate the magnitude of this relationship, if the Mechanical Turk workers assigned a certain code to an explanation (e.g., "inherent"), that increased its odds of being coded the same way by the researchers by over $230 \%$. This result suggests substantial convergence among the raters, even ones with minimal training on the distinction between inherent and extrinsic explanations.

\section{Results and discussion}

As a manipulation check, we computed each participant's median response time across the ten trials and then compared these medians across conditions. Consistent with the design of the study, the participants in the nonspeeded condition spent more time generating their explanations than did the participants in the speeded condition (average median response times $=38.1$ and $13.7 \mathrm{~s}$, respectively; $S D \mathrm{~s}=2.47$ and 0.20$), t(200)=9.67, p<$ .001 .

Effects of time pressure manipulation Our main prediction was that the explanations in the speeded condition, which mimicked the conditions under which many everyday explanations are generated, would show a stronger skew toward easily retrievable inherent information than would the explanations in the nonspeeded condition. With additional time, participants in the nonspeeded condition might retrieve and use less-accessible extrinsic facts as well, which should reduce the inherence bias in their explanations. In other words, we predicted a significant interaction between condition (speeded vs. nonspeeded) and explanation content (inherent vs. extrinsic), with the explanations in the speeded condition showing a greater imbalance between inherent and extrinsic content than those in the nonspeeded condition. To test this prediction, we conducted a mixed-effects logistic regression with the following dichotomous predictors: condition (speeded $=0$ vs. nonspeeded $=1$ ), explanation content (extrinsic $=0$ vs. inherent $=1$ ), and their interaction. The predictors were 


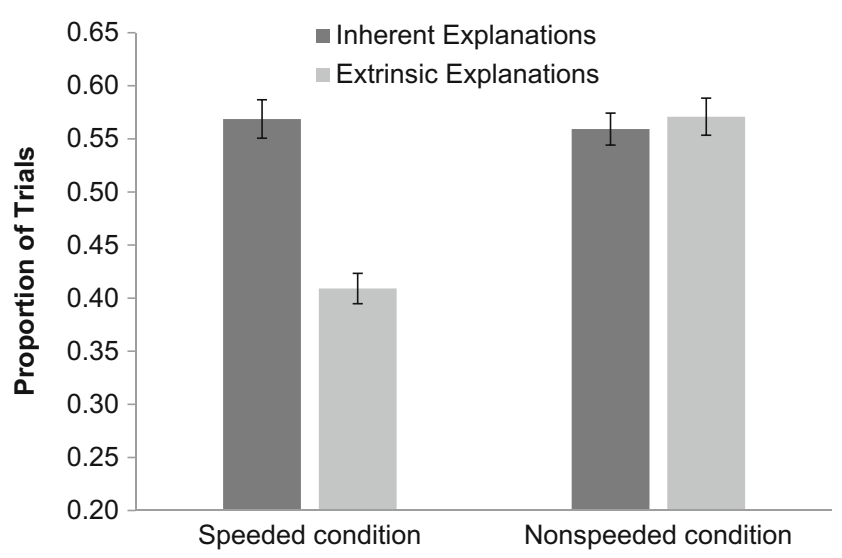

Fig. 1 Proportions of trials on which participants generated explanations containing inherent and extrinsic information in the speeded and nonspeeded conditions of Study 4

mean-centered in order to facilitate interpretation of the coefficients. The model included random intercepts for both participants and items, and a random slope for condition over items only (since condition did not vary within subjects). Models with additional random slopes failed to converge.

The results revealed the predicted interaction, $b=-0.69, S E=$ 0.13 , bootstrapped 95\% CI: $[-0.94,-0.47]$ (see Fig. 1 and Table 11 for the full model results). In the speeded condition, participants' explanations appealed to inherent facts significantly more often than to extrinsic facts $(M \mathrm{~s}=56.9 \%$ and $40.9 \%$ of trials, respectively; $S D \mathrm{~s}=18.0$ and 14.2), $b=0.64, S E=0.09$, bootstrapped $95 \% \mathrm{CI}$ : [0.49, 0.85]. In contrast, the explanations of participants in the nonspeeded condition relied roughly equally often on inherent and extrinsic information $(M \mathrm{~s}=55.9 \%$ and $57.1 \%, S D \mathrm{~s}=15.2$ and 17.7), $b=-0.05, S E=0.09$, bootstrapped 95\% CI: [-0.21, 0.13].

To clarify, the fact that participants in the nonspeeded condition relied on inherent and extrinsic information equally often doesn't necessarily mean that they overcame the inherence bias in explanation. The term "bias" signifies a departure from the normatively correct response. While we cannot be certain of the correct answers to the ten "why?" questions in this study, chances are that virtually all of them involve an extrinsic element; after all, these questions concern social conventions, such as that engagement rings have diamonds or that women wear long hair, that have likely been shaped by countless historical and cultural forces. Thus, we suspect that participants' explanations in the nonspeeded condition (even though balanced between inherent and extrinsic information) were still systematically biased relative to the correct explanations, in that they probably underused extrinsic information and overused inherent information.

Relationship with response latencies Our hypothesis concerning the differential accessibility of inherent and extrinsic information during the process of explaining makes an additional pair of predictions: First, the longer that participants take to think about their response, the more likely they might be to retrieve relevant but less-accessible extrinsic information, and thus the more likely they might be to generate an explanation containing such information. Second, deliberation time should not be related to the likelihood of relying on inherent information; this information comes to mind quickly (see Studies 1 and 2) and should thus be available to the explainer throughout the deliberation period.

We explored these predictions with the data from the nonspeeded condition only, largely because the variability in response times in the speeded condition (in which everyone was cut off after $15 \mathrm{~s}$ ) was minimal. Specifically, we conducted two mixed-effects logistic regressions that modeled the probability that an explanation would contain inherent and, separately, extrinsic information as a function of the number of seconds participants took to generate that explanation. ${ }^{10}$ Both the intercept and the slope of this relationship were allowed to vary randomly across subjects and across items. As predicted, the longer that participants spent thinking about their response on a certain trial, the more likely they were to generate an explanation that invoked extrinsic information, $b=0.018, S E=0.004$, bootstrapped $95 \%$ CI: $[0.010,0.026]$ (see Table 12 for the full results). More concretely, each additional $10 \mathrm{~s}$ spent thinking about an explanation was associated with a $17.8 \%$ rise in the odds that the explanation would contain extrinsic information. In contrast, latencies were not related to the likelihood of generating an explanation containing inherent information, $b=-0.002, S E=0.005$, bootstrapped 95\% CI: $[-0.011,0.008]$. Because inherent facts are easily accessible, they are equally likely to be included in explanations with short and long latencies.

The findings from Study 4 provide evidence for an inherence heuristic in explanation. Explanations containing inherent information about the entities in the explanandum were more prevalent when participants generated answers quickly, which suggests that inherent information is easily retrieved and used to construct off-the-cuff explanatory intuitions. In contrast, when participants were allowed (and took) ample time to come up with an explanation, extrinsic information was retrieved as well and was incorporated into their explanatory judgments. Thus, when reasoners are motivated to arrive at an accurate explanation - and also have the cognitive resources to dedicate to this task - they can partly overcome the strong inherence bias that characterizes quicker explanations.

\section{General discussion}

To make sense of everyday life, people must retrieve relevant information from memory to construct explanations. Although the role of memory in the process of generating

\footnotetext{
${ }^{10}$ This latency variable was positively skewed. Applying a natural logarithm transformation reduced the skew substantially, but the results of the mixedeffects logistic regressions with the transformed and untransformed latency variables showed the same pattern of significant relationships. For simplicity, we report the results with the untransformed variable.
} 
Table 11 Mixed-effects logistic regression predicting the likelihood of generating an explanation based on condition, explanation content, and the interaction of these two variables (Study 4)

\begin{tabular}{|c|c|c|c|c|}
\hline Fixed Effects & Estimate & $S E$ & \multicolumn{2}{|c|}{ Bootstrapped 95\% CI } \\
\hline (Intercept) & 0.11 & 0.04 & 0.05 & 0.19 \\
\hline Condition $($ speeded $=0 ;$ nonspeeded $=1$ ) & 0.31 & 0.06 & 0.18 & 0.42 \\
\hline Explanation Content $($ extrinsic $=0$; inherent $=1)$ & 0.29 & 0.06 & 0.18 & 0.41 \\
\hline Condition $\times$ Explanation Content & -0.69 & 0.13 & -0.94 & -0.47 \\
\hline Random Effects & Predictor Variable & & \multicolumn{2}{|l|}{$S D$} \\
\hline Grouping variable: Subject & & Intercept & \multicolumn{2}{|l|}{$<0.001$} \\
\hline Grouping variable: Item & & Intercept & \multicolumn{2}{|l|}{0.06} \\
\hline & Condition & Slope & \multicolumn{2}{|l|}{0.03} \\
\hline
\end{tabular}

Observations: 4,040; Subjects: 202; Items: 10

explanations is widely acknowledged, little research has actually investigated how the dynamics of memory retrieval shape the explanations that people come up with (e.g., Thomas et al., 2008). The inherence heuristic account (Cimpian \& Salomon, 2014a, b) elucidates one potential constraint that memory processes impose on explanation. Specifically, this account proposes that everyday explanations tend to be constructed on the basis of information that is most easily retrieved from memory, which often concerns the inherent, constitutive features of the entities involved. Although previous research on the inherence heuristic has already provided support for several predictions of this account (e.g., Cimpian \& Steinberg, 2014; Hussak \& Cimpian, 2015; Salomon \& Cimpian, 2014), two key claims have (until now) remained untested: namely, that (1) inherent facts are generally more accessible than noninherent ones, and (2) this accessibility differential gives rise to an inherence bias in the content of spontaneous explanations. The present research has provided evidence for these two claims across four studies that employed diverse methodologies: Not only did inherent facts come to mind often (Study 1) and quickly (Study 2) for a wide range of entities, but these facts were also readily retrieved in the service of explanation across a wide range of explananda (Studies 3 and 4). Together, these results support the proposal that the explanations generated during ordinary cognitive activity overuse inherent facts about the entities in the explanandum because these facts are more easily accessible in memory than equally relevant extrinsic facts.

\section{Consequences of relying on an inherence heuristic}

Given that explanations form the basis for how people understand much of the world, a bias in the process by which these judgments are generated is likely to have far-reaching consequences. To illustrate, this inherence bias in explanation has been shown to shape sociopolitical reasoning - people's understanding of, and attitudes toward, the workings of their society (Hussak \& Cimpian, 2015). Consider, for instance, a pervasive feature of human societies: status hierarchies between groups (e.g., that Group A is richer than Group B). When reasoning about such hierarchies, relying on accessible inherent information about the groups involved often results in their disparities appearing natural and legitimate (e.g., Group A is richer because they are inherently smarter, so they deserve their higher

Table 12 Mixed-effects logistic regression predicting the likelihood of generating an explanation containing extrinsic information as a function of explanation latency in the nonspeeded condition of Study 4

\begin{tabular}{llll}
\hline $\begin{array}{l}\text { Fixed Effects } \\
\text { (Intercept) }\end{array}$ & Estimate & SE & Bootstrapped 95\% CI \\
Explanation latency & -0.33 & 0.26 & -0.80 \\
& 0.02 & 0.004 & 0.01 \\
Random Effects & Predictor Variable & & $S D$ \\
Grouping variable: Subject & & Intercept & 0.21 \\
& Expl. latency & Slope & 0.03 \\
Grouping variable: Item & & Intercept & 0.66 \\
& Expl. latency & Slope & 0.002 \\
\hline
\end{tabular}

Observations: 1,029; Subjects: 103; Items: 10 
status). As a result, people tend to accept the status quo more readily than they might otherwise. Because of the immediate accessibility of inherent information, people likewise overestimate the stability and immutability of current societal structures (Cimpian \& Steinberg, 2014). If Group A is understood to have high status because of their smarts, it may also appear to a reasoner that this group has always been, and will always be, at the top of the socioeconomic ladder-and perhaps even that they ought to be there (Tworek \& Cimpian, 2016). These considerations illustrate the profound impact that the inherence bias in explanation is likely to have on how individuals understand and interact with the world.

\section{Directions for future work}

The present findings raise several interesting questions and potential directions for future work. In particular, it would be worthwhile to investigate what moderates the inherence bias in explanation. We consider two possible moderators here. First, a potential moderator is the scope of the explanandum (narrow vs. broad). Information about circumstances, external constraints, and so forth, may be more easily called to mind when explaining a particular event (e.g., why Sally got a bad grade on her math test) than when explaining a broad pattern (e.g., why women tend to underperform in math; Cimpian \& Markman, 2009, 2011). If extrinsic information is indeed more accessible when people are explaining specific events, the inherence bias may be somewhat attenuated for these explananda (Cimpian \& Salomon, 2014b). However, as has been suggested by the literature on the correspondence bias (the tendency to overattribute others' behaviors to dispositional factors; e.g., Gilbert \& Malone, 1995) and by the results of Studies $3 \mathrm{~b}$ and $3 \mathrm{c}$ (in which many of the stimuli concerned specific events), inherent information often remains highly accessible even when explaining individual cases/events, and as a result, this information is still overrepresented in the explanations generated. Consistent with this possibility, ongoing work in our lab suggests that the correspondence bias relies on the same cognitive mechanisms as the inherence heuristic investigated here, and thus may be a particular instantiation of this phenomenon (Storage \& Cimpian, 2015).

Second, cultural factors might also moderate the memory accessibility of inherent facts, and thus their likelihood of being used in explanations. For instance, research on the correspondence bias has found that in East Asian cultures situational attributions (i.e., extrinsic explanations) are more common than dispositional attributions (i.e., inherent explanations) when interpreting behavior (e.g., Choi, Nisbett, \& Norenzayan, 1999; Morris \& Peng, 1994). This phenomenon suggests that culturespecific factors might influence how likely one is to retrieve and rely on inherent information when constructing an explanation. To speculate, it seems unlikely to us that such cultural influences would completely undo the accessibility advantage for inherent facts, which is more or less a function of how our cognitive systems are set up; rather, culture may simply attenuate this basic advantage for inherent information. At this point, however, this is an open empirical question.

\section{Conclusion}

Explanation is a vital cognitive tool by which we abstract meaning from our experiences. The present research contributes to theories of explanation by investigating the role of memory retrieval in the process of constructing explanations. Consistent with key (but previously untested) assumptions of the inherence heuristic account (Cimpian \& Salomon, 2014a, b), the four studies reported here suggest that inherent facts are more easily accessible in memory than noninherent facts, and that this accessibility difference in turn biases the content of everyday explanations toward inherence. This bias has deep, pervasive consequences for how people understand the world.

Author noteWe are grateful to our participants, to the Cognitive Development Lab at the University of Illinois for research assistance and helpful discussion, and to Zach Horne, John Hummel, Sunny Khemlani, and Brian Ross for their insightful comments on a previous draft of the manuscript. This research was supported by a Graduate Research Fellowship from the National Science Foundation (L.J.H.) and by research funds from the University of Illinois and New York University (A.C.).

\section{Appendix}

Table 13 The items used in Studies 1 and 2

\begin{tabular}{|c|c|c|c|c|}
\hline \multicolumn{2}{|l|}{$\begin{array}{l}\text { STUDY 1 } \\
\text { (Sample 1) }\end{array}$} & \multicolumn{2}{|l|}{$\begin{array}{l}\text { STUDY 1 } \\
\text { (Sample 2) }\end{array}$} & STUDY 2 \\
\hline Accordion & Motorcycle & Alligator & Mouse & Baseball \\
\hline Apartment & Necklace & Ambulance & Mushroom & Book \\
\hline Asparagus & Nectarine & Basket & Oak & Bread \\
\hline Axe & Nightgown & Bat & Octopus & Breakfast \\
\hline Barrel & Nylons & Bathtub & Olive & Coin \\
\hline Bed & Oriole & Bedroom & Oven & Dress \\
\hline Beets & Pajamas & Biscuit & Pants & Harmonica \\
\hline Blackbird & Peacock & Boat & Parka & House \\
\hline Blueberry & Pencil & Bolts & Pear & Language \\
\hline Bow & Pickle & Bomb & Peas & Lion \\
\hline Bowl & Platypus & Book & Pen & Pencil \\
\hline $\mathrm{Bra}$ & Porcupine & Bookcase & Pepper & Skateboarc \\
\hline Bracelet & Pot & Bow & Pie & Telephone \\
\hline Bungalow & Projector & Bread & Pier & Wedding \\
\hline Buzzard & Python & Broom & Pig & Winter \\
\hline Cake & Raccoon & Cap & Pine & \\
\hline Camisole & Raisin & Cape & Pistol & \\
\hline Canoe & Rattlesnake & Caribou & Pumpkin & \\
\hline Cat & Ring & Cart & Pyramid & \\
\hline Chicken & Robin & Cheetah & Radish & \\
\hline Chipmunk & Rope & Chickadee & Rhubarb & \\
\hline Coma & Ruler & Church & Rooster & \\
\hline Crane & Scissors & Cigarette & Scooter & \\
\hline Cup & Seal & Closet & Screws & \\
\hline Cushion & Shell & Coconut & Seaweed & \\
\hline
\end{tabular}


Table 13 (continued)

\begin{tabular}{|c|c|c|c|c|}
\hline \multicolumn{2}{|l|}{$\begin{array}{l}\text { STUDY 1 } \\
\text { (Sample 1) }\end{array}$} & \multicolumn{2}{|l|}{$\begin{array}{l}\text { STUDY 1 } \\
\text { (Sample 2) }\end{array}$} & STUDY 2 \\
\hline Dandelion & Ship & Corn & Shelves & \\
\hline Dish & Shoes & Cougar & Shield & \\
\hline Dishwasher & Shotgun & Crowbar & Shirt & \\
\hline Falcon & Slingshot & Deer & Shovel & \\
\hline Faucet & Snail & Desk & Socks & \\
\hline Flute & Sofa & Doll & Spatula & \\
\hline Fox & Sparrow & Dolphin & Spinach & \\
\hline Frog & Spoon & Dress & Swan & \\
\hline Garlic & Surfboard & Dresser & Tank & \\
\hline Gate & Tank & Eagle & Tent & \\
\hline Goat & Tap & Earmuffs & Tie & \\
\hline Goldfish & Thimble & Elk & Trombone & \\
\hline Gorilla & Tiger & Emerald & Trousers & \\
\hline Hammer & Tomahawk & Envelope & Trout & \\
\hline Hare & Train & Finch & Tuba & \\
\hline Harpoon & Turtle & Fork & Tuna & \\
\hline Honeydew & Veil & Fridge & Turkey & \\
\hline Hosiery & Wheelbarrow & Grasshopper & Vulture & \\
\hline Iguana & Whistle & Grenade & Walrus & \\
\hline Jeep & Woodpecker & Groundhog & Willow & \\
\hline Jet & Zucchini & Hoe & Wrench & \\
\hline Kettle & & Horse & & \\
\hline Lamp & & Jacket & & \\
\hline Machete & & Lantern & & \\
\hline Mackerel & & Leopard & & \\
\hline Marble & & Limousine & & \\
\hline Mat & & Mink & & \\
\hline Medal & & Mirror & & \\
\hline Microwave & & Mittens & & \\
\hline
\end{tabular}

\section{References}

Ahn, W.-K., Kalish, C. W., Medin, D. L., \& Gelman, S. A. (1995). The role of covariation versus mechanism information in causal attribution. Cognition, 54, 299-352.

Ashcraft, M. H. (1978). Property norms for typical and atypical items from 17 categories: A description and discussion. Memory \& Cognition, 6, 227-232. doi:10.3758/BF03197450

Barr, R. A., \& Caplan, L. J. (1987). Category representations and their implications for category structure. Memory \& Cognition, 15, 397-418.

Bates, D. M. (2007). Linear mixed model implementation in lme4. University of Wisconsin-Madison.

Bates, D., Mächler, M., Bolker, B., \& Walker, S. (2014). Fitting linear mixed-effects models using lme4. Journal of Statistical Software, 67(1), 1-48. arXiv:1406.5823

Bian, L., Leslie, S. J., \& Cimpian, A. (2017). Gender stereotypes about intellectual ability emerge early and influence children's interests. Science, 355, 389-391. doi:10.1126/science.aah6524

Caplan, L. J., \& Barr, R. A. (1991). The effects of feature necessity and extrinsicity on gradedness of category membership and class inclusion relations. British Journal of Psychology, 82, 427-440. doi:10. 1111/j.2044-8295.1991.tb02410.x

Carey, S. (1985). Conceptual change in childhood. Cambridge: MIT Press.

Chi, M. T., Bassok, M., Lewis, M. W., Reimann, P., \& Glaser, R. (1989). Self-explanations: How students study and use examples in learning to solve problems. Cognitive Science, 13, 145-182.
Choi, I., Nisbett, R. E., \& Norenzayan, A. (1999). Causal attribution across cultures: Variation and universality. Psychological Bulletin, $125,47-63$.

Cimpian, A. (2015). The inherence heuristic: Generating everyday explanations. In R. Scott \& S. Kosslyn (Eds.), Emerging trends in the social and behavioral sciences (pp. 1-15). Hoboken: Wiley.

Cimpian, A., Brandone, A. C., \& Gelman, S. A. (2010). Generic statements require little evidence for acceptance but have powerful implications. Cognitive Science, 34, 1452-1482. doi:10.1111/j.15516709.2010.01126.x

Cimpian, A., \& Markman, E. M. (2009). Information learned from generic language becomes central to children's biological concepts: Evidence from their open-ended explanations. Cognition, 113, 14-25. doi:10. 1016/j.cognition.2009.07.004

Cimpian, A., \& Markman, E. M. (2011). The generic/nongeneric distinction influences how children interpret new information about social others. Child Development, 82, 471-492. doi:10.1111/j.1467-8624. 2010.01525.x

Cimpian, A., \& Salomon, E. (2014a). The inherence heuristic: An intuitive means of making sense of the world, and a potential precursor to psychological essentialism. Behavioral and Brain Sciences, 37, 461-480. doi:10.1017/S0140525X13002197

Cimpian, A., \& Salomon, E. (2014b). Refining and expanding the proposal of an inherence heuristic in human understanding. Behavioral and Brain Sciences, 37, 506-527. doi:10.1017/ S0140525X14000028

Cimpian, A., \& Steinberg, O. D. (2014). The inherence heuristic across development: Systematic differences between children's and adults' explanations for everyday facts. Cognitive Psychology, 75, 130-154. doi:10.1016/j.cogpsych.2014.09.001

Collins, A. M., \& Quillian, M. R. (1969). Retrieval time from semantic memory. Journal of Verbal Learning and Verbal Behavior, 8, 240 247. doi:10.1016/S0022-5371(69)80069-1

Craik, F. I. M., \& Lockhart, R. S. (1972). Levels of processing: A framework for memory research. Journal of Verbal Learning and Verbal Behavior, 11, 671-684. doi:10.1016/S0022-5371(72)80001-X

Evans, J. S. B. T. (2006). The heuristic-analytic theory of reasoning: Extension and evaluation. Psychonomic Bulletin \& Review, 13, 378-395. doi:10.3758/BF03193858

Evans, J. S. B. T. (2008). Dual-processing accounts of reasoning, judgment, and social cognition. Annual Review of Psychology, 59, 255 278. doi:10.1146/annurev.psych.59.103006.093629

Evans, J. S. B. T., \& Stanovich, K. E. (2013). Dual-process theories of higher cognition: Advancing the debate. Perspectives on Psychological Science, 8, 223-241. doi:10.1177/ 1745691612460685

Feldman, J. (2003). The simplicity principle in human concept learning. Current Directions in Psychological Science, 12, 227-232.

Gelman, S. (2003). The essential child: Origins of essentialism in everyday thought. New York: Oxford University Press.

Gentner, D., \& Kurtz, K. (2005). Relational categories. In W.-K. Ahn, R. Goldstone, B. Love, A. Markman, \& P. Wolff (Eds.), Categorization inside and outside the laboratory: Essays in honor of Douglas L. Medin (pp. 151-175). Washington, DC: American Psychological Association.

Gilbert, D. T., \& Malone, P. S. (1995). The correspondence bias. Psychological Bulletin, 117, 21-38. doi:10.1037/0033-2909.117.1.21

Gilovich, T., Griffin, D., \& Kahneman, D. (2002). Heuristics and biases: The psychology of intuitive judgment. Cambridge: Cambridge University Press.

Gopnik, A. (1998). Explanation as orgasm. Minds and Machines, 8, 101-118.

Green, P., \& MacLeod, C. J. (2016). SIMR: An R package for power analysis of generalized linear mixed models by simulation. Methods in Ecology and Evolution, 7, 493-498.

Halford, G. S., Wilson, W. H., \& Phillips, S. (1998). Processing capacity defined by relational complexity: Implications for comparative, 
developmental, and cognitive psychology. Behavioral and Brain Sciences, 21, 803-864.

Hampton, J. A. (1979). Polymorphous concepts in semantic memory. Journal of Verbal Learning and Verbal Behavior, 18, 441-461.

Hampton, J. A. (1981). An investigation of the nature of abstract concepts. Memory \& Cognition, 9, 149-156.

Hummel, J. E., \& Holyoak, K. J. (1997). Distributed representations of structure: A theory of analogical access and mapping. Psychological Review, 104, 427-466. doi:10.1037/0033-295X.104.3.427

Hussak, L. J., \& Cimpian, A. (2015). An early-emerging explanatory heuristic promotes support for the status quo. Journal of Personality and Social Psychology, 109, 739-752. doi:10.1037/ pspa0000033

Johnson, S. G. B., \& Keil, F. C. (2014). Causal inference and the hierarchical structure of experience. Journal of Experimental Psychology: General, 143, 2223-2241.

Jorgensen, C. C., \& Kintsch, W. (1973). The role of imagery in the evaluation of sentences. Cognitive Psychology, 4, 110-116.

Kahneman, D. (2011). Thinking, fast and slow. New York: Farrar, Straus and Giroux.

Kahneman, D., \& Frederick, S. (2002). Representativeness revisited: Attribute substitution in intuitive judgment. In T. Gilovich, D. Griffin, \& D. Kahneman (Eds.), Heuristics and biases: The psychology of intuitive judgment (pp. 49-81). Cambridge: Cambridge University Press.

Kahneman, D., \& Tversky, A. (1973). On the psychology of prediction. Psychological Review, 80, 237-251. doi:10.1037/h0034747

Keil, F. C. (2006). Explanation and understanding. Annual Review of Psychology, 57, 227-254.

Lagnado, D. A., \& Sloman, S. A. (2006). Time as a guide to cause. Journal of Experimental Psychology: Learning, Memory, and Cognition, 32, 451-460.

Legare, C. H., \& Lombrozo, T. (2014). Selective effects of explanation on learning during early childhood. Journal of Experimental Child Psychology, 126, 198-212.

Legrenzi, P., Girotto, V., \& Johnson-Laird, P. N. (1993). Focussing in reasoning and decision making. Cognition, 49, 37-66.

Lewis, D. (1983). Extrinsic properties. Philosophical Studies, 44, $197-200$

Lombrozo, T. (2006). The structure and function of explanations. Trends in Cognitive Sciences, 10, 464-470.

Lombrozo, T. (2007). Simplicity and probability in causal explanation. Cognitive Psychology, 55, 232-257.

Lombrozo, T. (2012). Explanation and abductive inference. In K. Holyoak \& R. Morrison (Eds.), Oxford handbook of thinking and reasoning (pp. 260-276). New York: Oxford University Press.

Lombrozo, T., \& Carey, S. (2006). Functional explanation and the function of explanation. Cognition, 99, 167-204.

Lombrozo, T., \& Gwynne, N. Z. (2014). Explanation and inference: Mechanistic and functional explanations guide property generalization. Frontiers in Human Neuroscience, 8, 700.

McRae, K., Cree, G. S., Seidenberg, M. S., \& McNorgan, C. (2005). Semantic feature production norms for a large set of living and nonliving things. Behavior Research Methods, 37, 547-559. doi: 10.3758/BF03192726

Mehlhorn, K., Taatgen, N. A., Lebiere, C., \& Krems, J. F. (2011). Memory activation and the availability of explanations in sequential diagnostic reasoning. Journal of Experimental Psychology: Learning, Memory, and Cognition, 37, 1391-1411.

Morris, M. W., \& Peng, K. (1994). Culture and cause: American and Chinese attributions for social and physical events. Journal of Personality and Social Psychology, 67, 949-971.

Murphy, G. L., \& Allopenna, P. D. (1994). The locus of knowledge effects in concept learning. Journal of Experimental Psychology: Learning, Memory, and Cognition, 20, 904-919. doi:10.1037/ 0278-7393.20.4.904
Paivio, A., Yuille, J. C., \& Madigan, S. A. (1968). Concreteness, imagery, and meaningfulness values for 925 nouns. Journal of Experimental Psychology, 76((1, Pt. 2)), 1-25. doi:10.1037/h0025327

Pothos, E. M., \& Chater, N. (2002). A simplicity principle in unsupervised human categorization. Cognitive Science, 26, 303-343.

Rosch, E., Mervis, C. B., Gray, W. D., Johnson, D. M., \& Boyes-Braem, P. (1976). Basic objects in natural categories. Cognitive Psychology, 8, 382-439. doi:10.1016/0010-0285(76)90013-X

Rozenblit, L., \& Keil, F. (2002). The misunderstood limits of folk science: An illusion of explanatory depth. Cognitive Science, 26, 521-562.

Salomon, E., \& Cimpian, A. (2014). The inherence heuristic as a source of essentialist thought. Personality and Social Psychology Bulletin, 40, 1297-1315. doi:10.1177/0146167214541659

Schwarz, N., \& Clore, G. L. (1983). Mood, misattribution, and judgements of well-being: Informative and directive functions of affective states. Journal of Personality and Social Psychology, 45, 513-523.

Shah, A. K., \& Oppenheimer, D. M. (2008). Heuristics made easy: An effort-reduction framework. Psychological Bulletin, 134, 207-222. doi:10.1037/0033-2909.134.2.207

Sloman, S. (2005). Causal models: How people think about the world and its alternatives. New York: Oxford University Press.

Snijders, T. A. B. (2005). Power and sample size in multilevel linear models. In B. S. Everitt \& D. C. Howell (Eds.), Encyclopedia of statistics in behavioral science (Vol. 3, pp. 1570-1573). Chichester: Wiley.

Spelke, E. S., \& Kinzler, K. D. (2007). Core knowledge. Developmental Science, 10, 89-96.

Spiller, S. A. (2011). Opportunity cost consideration. Journal of Consumer Research, 38, 595-610. doi:10.1086/660045

Spreen, O., \& Schulz, R. W. (1966). Parameters of abstraction, meaningfulness, and pronunciability for 329 nouns. Journal of Verbal Learning and Verbal Behavior, 5, 459-468.

Stanovich, K. E., \& West, R. F. (2000). Individual differences in reasoning: Implications for the rationality debate? Behavioral and Brain Sciences, 23, 645-726.

Sutherland, S. L., \& Cimpian, A. (2015). An explanatory heuristic gives rise to the belief that words are well suited for their referents. Cognition, 143, 228-240.

Thomas, R., Dougherty, M. R., \& Buttaccio, D. R. (2014). Memory constraints on hypothesis generation and decision making. Current Directions in Psychological Science, 23, 264-270.

Thomas, R. P., Dougherty, M. R., Sprenger, A. M., \& Harbison, J. I. (2008). Diagnostic hypothesis generation and human judgment. Psychological Review, 115, 155-185. doi:10.1037/0033-295X.115. 1.155

Tversky, A., \& Kahneman, D. (1973). Availability: A heuristic for judging frequency and probability. Cognitive Psychology, 5, 207-232. doi:10.1016/0010-0285(73)90033-9

Tversky, A., \& Kahneman, D. (1974). Judgment under uncertainty: Heuristics and biases. Science, 185, 1124-1131. doi:10.1126/ science.185.4157.1124

Tversky, A., \& Kahneman, D. (1983). Extensional versus intuitive reasoning: The conjunction fallacy in probability judgment. Psychological Review, 90(4), 293-315.

Tversky, B., \& Hemenway, K. (1984). Objects, parts, and categories. Journal of Experimental Psychology: General, 113, 169-193.

Tworek, C. M., \& Cimpian, A. (2016). Why do people tend to infer "ought" from "is"? The role of biases in explanation. Psychological Science, 27, 1109-1122. doi:10.1177/ 0956797616650875

Vinson, D. P., \& Vigliocco, G. (2008). Semantic feature production norms for a large set of objects and events. Behavior Research Methods, 40, 183-190. doi:10.3758/BRM.40.1.183

Walker, C. M., Lombrozo, T., Legare, C. H., \& Gopnik, A. (2014). Explaining prompts children to privilege inductively rich properties. Cognition, 133, 343-357. 
Weatherson, B., \& Marshall, D. (2014). Intrinsic vs. extrinsic properties. In E. Zalta (Ed.), The Stanford encyclopedia of philosophy. Retrieved from http://plato.stanford.edu/entries/intrinsic-extrinsic/

Weber, E. U., Johnson, E. J., Milch, K. F., Chang, H., Brodscholl, J. C., \& Goldstein, D. G. (2007). Asymmetric discounting in intertemporal choice: A query-theory account. Psychological Science, 18, 516-523.

Wellman, H. M. (2011). Reinvigorating explanations for the study of early cognitive development. Child Development Perspectives, 5, 33-38.
West, S. G., Ryu, E., Kwok, O. M., \& Cham, H. (2011). Multilevel modeling: Current and future applications in personality research. Journal of Personality, 79, 2-50.

Williams, J. J., \& Lombrozo, T. (2010). The role of explanation in discovery and generalization: Evidence from category learning. Cognitive Science, 34, 776-806.

Wu, L.-L., \& Barsalou, L. W. (2009). Perceptual simulation in conceptual combination: Evidence from property generation. Acta Psychologica, 132, 173-189. doi:10.1016/j.actpsy.2009.02.002 